\title{
Characterizing the Rogues and Smooth Pairs of Cronobacter sakazakii Involved in Biofilm Formation and Long-Term Survival
}

\author{
Lan Hu* and Sherile K. Curtis
}

CFSAN, FDA, Laurel, MD 20708, USA

*Corresponding author

\author{
A B S T R A C T
}

Ke y w o r d s
$\begin{aligned} & \text { Cronobacter, } \\ & \text { Biofilm, Foodborne } \\ & \text { pathogens, Rugose } \\ & \text { phenotype change, } \\ & \text { Autoaggression, } \\ & \text { Bacterial resistance. }\end{aligned}$
Article Info
$\begin{aligned} & \text { Accepted: } \\ & \text { 29 September } 2017 \\ & \text { Available Online: } \\ & \text { 10 October } 2017\end{aligned}$

Cronobacter species are emerging foodborne pathogens that cause severe sepsis, meningitis, and necrotizing enterocolitis in neonates and infants. Many bacteria use phase variation such as smooth to rugose phenotype change to adapt and survive in stressful environments. In this study we developed two stable smooth and rugose pairs by sequentially streaking a single rugose or smooth colony of $C$. sakazakii on Trypticase Soy Agar at $37^{\circ} \mathrm{C}$ to understand the roles of the smooth and rugose phase change in Cronobacter. The rugose-positive strains produced significantly more biofilms and cell autoaggregation than their rugose-negative counterparts. More bacteria of rugose-positive C. sakazakii persisted for five months under desiccated growth environment than their smooth counterparts. Our study showed that $C$. sakazakii did not express curli, but possessed cellulose $b c s A B C$ genes in both rugose and smooth pairs. The data show that the rugose phenotype of Cronobacter allows for more biofilm formation and cell autoaggregation, and the rugose variants could survive much longer than the smooth counterparts in desiccated environment. These results suggest that the smooth to rugose phenotype change plays an important role in Cronobacter survival and persistence in harsh environments.

\section{Introduction}

Cronobacter species are peritrichous flagella, Gram-negative bacilli, and emerging opportunistic foodborne pathogens (Farmer et al., 1980; Iversen et al., 2008; Jarada et al., 2014). Although the epidemiology and reservoir of Cronobacter are still not understood very well, powdered infant formula has been considered as the principal route of transmission among infants (Beuchat et al., 2009; Himelright et al., 2002; Hunter and Bean, 2013; Tall et al., 2015). Cronobacter also cause urinary tract infections, septicemia, and catheter-associated wound infections in people of all ages, especially in the elderly and those with other diseases or immune-compromised individuals (Joseph et al., 2012). Cronobacter can survive in dried food, fresh produces, and fruit juices (Lin and Beuchat, 2007; Gurtler and Beuchat, 2007; Tall et al., 2015).

In response to environmental stresses, many pathogens undergo phase variation between rugose (also known as wrinkled or rdar) and smooth colony morphology. Although both variants of Vibrio and Salmonella are pathogenic and are found both in vivo and in vitro, the rugose phase variants form 
corrugated colonies, exhibit increased resistances to acids, low temperatures, osmotic pressure and oxidative stresses, and form more biofilms (Anriany et al., 2001; Beyhan et al., 2007; de Rezende et al., 2005; Hollenback et al., 2014; Morris et al., 1996; Rice et al., 1992; Wai et al., 1998; Yildiz and Schoolnik 1999; Yildiz et al., 2004). In Vibrio species, more surface polysaccharide (VPS) are produced in the rugose variants.

The increase is mediated by genes located in the VpsI (VpsA-K) and VpsII (VpsL-Q) loci (Yildiz and Schoolnik 1999). A microarray study of $V$. cholerae shows that smooth and rugose phase variation are directed by complex regulatory genes to raise the resistance of the organisms (Yildiz et al., 2004). A rugose (R) variant of $V$. vulnificus produces a large number of extracellular polysaccharides (EPS) matrix and form biofilms (Grau et al., 2005), while a smooth variant forms less biofilms. The rugose colony morphology and biofilm formation of $S$. typhimurium are associated with extracellular substances including curli, cellulose, LPS, EPS, and capsules, which are important in the bacterial resistances (Anriany et al., 2001; de Rezende et al., 2005).

Biofilm consists of surface attached microbial communities (single species or several species) and extracellular substances. Formation of biofilms on surfaces can be regarded as universal bacterial strategy for bacterial survival and growth (Kaplan, 2010; Hollenback et al., 2014). C. sakazakii formed biofilms on stainless steel and enteral feeding tubes have increased their resistances to disinfectants (Beuchat et al., 2009), and the biofilms also facilitated survival and persistence of the bacteria in food and food manufacturing environments (Breeuwer et al., 2003).

Currently, very little information is available on the phase variation involving in
Cronobacter and their pathogenic mechanisms. Rugosity may play an important role in Cronobacter survival and persistence in food and food processing environments. In this study, we tried to determine the possible advantages of rugose state in Cronobacter. The rugose and smooth pairs of $C$. sakazakii were compared in biofilm formation, cell autoaggregation, and long-term survival.

\section{Materials and Methods}

\section{Bacterial growth conditions}

C. sakazakii strain 713 and 632 were identified by using species-specific $r p o B$ and $c g c A$ assays described by Stoop et al., (2009), Lehner et al., (2012), and Carter et al., (2013). Cronobacter strains were stored at -80 $\mathrm{C}$ in Trypticase Soy Broth (TSB) (BBL, Cockeysville, MD) supplemented with $1 \%$ $\mathrm{NaCl}$ (TSBS) and 50\% glycerol. Frozen bacterial cultures were streaked onto Trypticase Soy Agar (TSA), Luria-Bertani (LB, Bacto) agar, or LB without salt (LBNS) agar plates or inoculated into tubes contained TSBS or LB broth, and incubated overnight at $37 \mathrm{C}$ or $28 \mathrm{C}$.

\section{Congo red and calcofluor binding assays}

These assays were applied to check the expression of rugose morphotypes and cellulose production (Chapman et al., 2002; $\mathrm{Hu}$ et al., 2015). In brief, bacteria were cultured on LB agar overnight at $37 \mathrm{C}$, and inoculated onto LBNS agar plates supplemented with $40 \mu \mathrm{g} / \mathrm{ml}$ Congo red (Sigma, St. Louis, MO) and $20 \mu \mathrm{g} / \mathrm{ml}$ Coomassie brilliant blue (Sigma), or 200 $\mu \mathrm{g} / \mathrm{ml}$ fluorescence brightener 28 (Sigma). The inoculated agar plates were incubated at $28 \mathrm{C}$ for $24 \mathrm{~h}$, and then moved to room temperature, and evaluated at $24 \mathrm{~h}, 48 \mathrm{~h}$, and $72 \mathrm{~h}$. Cellulose production was judged by viewing the florescence of the colonies under a $366 \mathrm{~nm}$ UV light. All isolates were screened 
in duplicates in each assay and repeated the assay three times. The images of colonies were taken by a Bio-Rad digital camera.

\section{Biofilm formation assay}

Detection and quantification of biofilm were performed with glass tubes $(11 \times 75 \mathrm{~mm})$ using the procedure of $\mathrm{Hu}$ et al., (2015) with slight modification. These strains were incubated in $\mathrm{TSB}$ at $37 \mathrm{C}$ or $28 \mathrm{C}$, shaking at $150 \mathrm{rpm}$ for $48 \mathrm{~h}$. Biofilm formation in the tubes (pellicles at the air-liquid interfaces) was visually tested. The tubes were washed twice with PBS, air-dried for $30 \mathrm{~min}$, stained with $0.1 \%$ crystal violet at room temperature for $30 \mathrm{~min}$, and washed twice with distilled water. The crystal violet bound to the biofilm was dissolved with $5 \mathrm{ml}$ of $95 \%$ ethanol for 30 min by shaking, $100 \mu \mathrm{l}$ per well was added to a 96-well plate (three wells for each sample), and absorbance was determined at $570 \mathrm{~nm}$ by a UV max microplate reader (Molecular Devices, Corp., Sunnyvale, CA). The biofilm assay was carried out in duplicates, and three independent experiments were performed for each strain. Results are presented as the mean \pm SD.

\section{Cell autoaggregation}

To determine cell aggregation, the strains grown overnight were inoculated into $5 \mathrm{ml}$ LB broth in a small glass tube with shaking at $37 \mathrm{C}$ or $28 \mathrm{C}$ for $48 \mathrm{~h}$, then left standing at room temperature for $1 \mathrm{~h}$. Cell aggregation was determined by visual estimation of the cell sediment at the bottom of the glass tubes (Gualdi et al., 2008). The assay was carried out at least three independent experiments.

\section{Long-term survival assay}

The assay was done following the method of Vestby et al., (2009) with slight modification. Ten microliter overnight cultures of $C$.
Sakazakii strain 713 and 632 were inoculated in $50 \mathrm{ml}$ sterile centrifuge tubes. Each tube contained $20 \mathrm{ml} \mathrm{LB}$ broth and an autoclaved microscope slide, and all tubes was incubated with shaking at $37^{\circ} \mathrm{C}$ or $28^{\circ} \mathrm{C}$. Two tubes without added bacteria served as negative controls. During incubation, biofilms were allowed to form on both sides of the slides. After $48 \mathrm{~h}$, the slides were washed twice in sterile saline, moved to empty sterile centrifuge tubes, and air-dried in a sterile Class II Biosafety cabinet hood overnight. The lids of the tubes with slides were loosely tightened, and placed at room temperature for 5 months for detecting bacterial long-term survival. After 5 months, the slides were moved to new sterile tubes with $20 \mathrm{ml}$ PBS, the biofilms on the slides were thoroughly scraped using a sterile cell scraper and were disrupted with sterile glass beads (20-30 nm diameter) by vortexing. The number of viable bacteria remained in each sample was determined by serially diluting the cell mixtures and plated in duplicates onto 5\% sheep blood TBS agar plates (Remel, Lenexa, KS) and incubated at 37 C. Data were presented as the mean number of recovered colonies $\pm \mathrm{SD}$ of triplicate wells from three independent experiments.

\section{Molecular typing}

Pulsed-field gel electrophoresis (PFGE) analysis of XbaI-digested genomic DNA was used to examine the genetic relatedness of Cronobacter rugose and smooth pairs. High molecular mass DNA in agarose plugs was prepared as reported by Herschleb et al., (2007). The DNA samples were digested with the restriction enzyme Xbal, and the plugs were loaded onto a $1.5 \%$ agarose gel in $0.5 \%$ TBE buffer (45 mM Tris, $45 \mathrm{mM}$ boric acid, 1 mM EDTA, $\mathrm{pH}$ 8.0). The DNA samples were subjected to separation in a CHEF-Mapper (Bio-Rad) using the flowing parameter: pulsetimes, $1-14 \mathrm{~s}$ for $5 \mathrm{~h}, 12-25 \mathrm{~s}$ for $10 \mathrm{~h}, 8-50 \mathrm{~s}$ 
for $4 \mathrm{~h}, 6 \mathrm{~V} \mathrm{~cm}-1 ; 120$ reorientation angle. The gels were stained with $0.1 \%$ ethidium bromide solution, and imaged with a Bio-Rad Gel/Chemo Doc System (Bio-Rad, Hercules, CA).

\section{Metabolic typing by VITEK 2}

VITEK® 2 compact system (BioMerieux, Hazelwood, MO) was employed to identify metabolic differences between the $C$. sakazakii rugose and smooth phase variants following the manufacturer's instruction. The bacteria were grown overnight in TSA broth at $37 \mathrm{C}$ with shaking, the colonies of a pure culture were suspended to a turbidity reading of $\sim 0.5$, and a Gram negative (GN) card was used.

\section{Motility assay}

Bacteria were grown on TSA overnight, and a single colony was inoculated into a motility test medium (Remel), and incubated in $37 \mathrm{C}$ for $24 \mathrm{~h}$. The bacterial motility was confirmed and the images of the bacterial motility were taken by a Bio-Rad digital camera.

\section{Transmission electron microscope (TEM)}

Cronobacter were grown overnight on TSA at 37 C. A bacteria suspension in $0.25-0.5 \%$ phosphotungstic acid ( $\mathrm{pH}$ 6.8) containing approximately $10^{6} \mathrm{CFU} / \mathrm{ml}$ was applied to a formavar-carbon-coated 300 mesh copper grids for $2 \mathrm{~min}$. The liquid was removed by blotting. The samples were air-dried and visualized under a JEOL JEM-1011 electron microscope using an accelerating voltage of $80 \mathrm{KV}$.

\section{PCR assay}

Cronobacter strains were cultured on TSA overnight at $37 \mathrm{C}$, and single colony was transferred to TSB, and incubated with shaking overnight. The DNA of the
Cronobacter strains was prepared by boiling cell culture in $100 \mu \mathrm{l}$ distilled water for 10 min served as DNA templates. Primers for detecting cellulose and flagella genes of Cronobacter were designed from the conservative sequences of $b \operatorname{cs} A B C, f l i C, f l g E$, and $f l g K$ of $C$. sakazakii strains (Table 1 ). GoTaq Green Master Mix (Promega Corp., Madison, WI) was used as manufacture's instruction. One $\mu \mathrm{M}$ of each primer and $1 \mu \mathrm{l}$ bacterial cell lysate (approximately $50 \mathrm{ng}$ DNA) were missed with PCR buffer. Distilled water served as a negative control. All PCR reactions were run in an Applied Biosystem's models 2720 thermal cycler (Applied Biosystems, Foster City, CL). The PCR assay started by $5 \mathrm{~min}$ incubation at $94 \mathrm{C}$, followed by 30 cycles of $30 \mathrm{sec}$ at $94 \mathrm{C}$, and $30 \mathrm{sec}$ at 55-60 C, and 1-2 min at $72 \mathrm{C}$, and terminated with a final extension period of $7 \mathrm{~min}$ at $72 \mathrm{C}$. PCR products were separated with $1.5 \%$ agarose gels and stained with $0.1 \%$ ethidium bromide solution, and imaged with a Bio-Rad Gel/Chemo Doc System.

\section{Statistical analyses}

Each experiment was performed in triplicate. The means of the biofilm formation were compared using Student's t-test.

\section{Results and Discussion}

\section{Isolation of rugose and smooth phase variants}

C. sakazakii 713 and 632 were grown on TSA plates at $37 \mathrm{C}$. To develop stable, phase variants, serial passages $(>20)$ of colonies from rugose or smooth phase variants were performed by sequentially streaking a single rugose or smooth colony every 3 days onto a fresh TSA plate at $37^{\circ} \mathrm{C}$. The stable rugose (rough and dry) colonies were designated as "rugose" (R) while the smooth and wet colonies were named "smooth" (S). The Cronobacter colonies were grown on LBNS 
supplemented with Congo red and Coommassie blue at $28 \mathrm{C}$. Figure 1 shows the colony morphotypes of $C$. Sakazakii strain 713 and 632 on LBNS agar supplemented with Congo red and Coomassie blue. Strain 713R and 632R were presented as brown, dry, and rough (Bdar) colonies while the $713 \mathrm{~S}$ was presented as smooth and light yellow colony (YAS) (Fig. 1). 632S showed smooth and light brown colonies.

\section{Comparing rugose and smooth pairs on biofilm formation and cell aggregation}

After incubating in TSB in glass tubes for 48 $\mathrm{h}$ at $37 \mathrm{C}$ or $28 \mathrm{C}$ with shaking, the formed biofilms were characterized by the presence of a pronounced ring at the air-liquid interface, and the production of the biofilm was assayed by crystal violet staining method. The quantity of biofilm formation of the strains was slightly different when the strains were grown at varying temperatures (Fig. 2). The biofilm formation of 713R at OD570 was $\sim 1.80$ at $37 \mathrm{C}$ (Fig. 2A) and $\sim 1.90$ at $28 \mathrm{C}$ (Fig. 2B). The rugose strains produced significantly more biofilms than their smooth counterparts at $37 \mathrm{C}$ and $28 \mathrm{C}($ all $\rho<0.01)$. These results indicated that Cronobacter rugose strains expressed greater biofilm formation at both temperatures than the smooth counterparts.

Cell aggregation is the auto-clumping of bacterial cells. C. sakazakii 713R and 632R produced large clumps in TSB, leading to rapid bacterial aggregation. Lesser cell aggregates were observed in the $713 \mathrm{~S}$ and $632 \mathrm{~S}$ cultures compared to their rugose counterparts (Table 2).

\section{Long-term survival of rugose and smooth pairs in biofilms}

After bacterial biofilms formed on the glass slides, the slides were washed, air-dried, and kept in sterile tubes for 5 months at room temperature. Then the biofilm on the slides were thoroughly scraped and the number of viable bacteria remained in each slide was determined by plate counts. Survival of 732R and $632 \mathrm{R}$ were significant higher than $713 \mathrm{~S}$ and 632S $(\rho<0.001)$ (Table 3). The results clearly indicated that Cronobacter could survive in desiccated biofilm communities for at least 5 months, and the ability of producing large quantities of biofilms by rugose variants provided greater survival and persistence advantages than that of their smooth phase variant counterparts.

\section{PFGE and VITEK typing of rugose and smooth pairs}

The genetic typing of strain 713 and 632 was assessed by XbaI-digested genomic DNA using PFGE. The PFGE analysis showed the DNA patterns of the rugose and smooth pairs. There were two distinctly different bands between $713 \mathrm{R}$ and $713 \mathrm{~S}$ in Figure 3. No obvious different patterns were identified between 632R and 632S. The patterns suggested that no remarkable genetic differences were found between the rugose and smooth variants. The difference in strain $713 \mathrm{R}$ and $713 \mathrm{~S}$ may not result from the phase change from rugose to smooth due to no similar common pattern changes between 632R and 632S. The VITEK 2 compact system is a fully automated system that performs bacterial identification by biochemical analysis using colorimetry. All strains were identified as C. sakazakii in this typing method. There are three different reactions between strain 713 (GGT+, BXYL-, and GlyA+) and strain 632 (GGT-, BXYL+, and GlyA-), and one reaction differed between 713R (ILATK+) and 713S (ILATK). No common differences were found between two rugose and smooth pairs. To understand if flagella, curli and cellulose cause the phase changes between strain $713 \mathrm{R}$ and $713 \mathrm{~S}$, 
further experiments were carried out.

Detection of motility of $C$. sakazakii 713 and 632

The motility test agar and transmission EM were used to check the bacterial motility and presence of flagella. The tubes with $0.6 \%$ TSA agar were incubated at $37 \mathrm{C}$, and were observed at 24 h, 48 h, and 72 h. Figure 4 I shows the images of motility tubes incubated for $24 \mathrm{~h}$ at $37 \mathrm{C}$. All strains except $713 \mathrm{~S}$ showed positive motility in the assay. EM observation of negative stained Cronobacter strains grown on TSA plates at $37 \mathrm{C}$ revealed flagella in $713 \mathrm{R}, 632 \mathrm{R}$ and $632 \mathrm{~S}$, but not in 713S (Fig. 4 II). The result confirmed that the lacking of motility in strain $713 \mathrm{~S}$ was resulted from no expression of its flagella.

Detection of cellulose $b c s A B C$ genes and expression in the rugose and smooth pairs

The rugosity of E. coli and Salmonella species were reported to relate to cellulose and curli of the organisms. PCR assay was employed to detect cellulose $b c s A B C$ genes in the rugose and smooth pairs, and all strains presented $b c s A B C$ genes (Table 4). The PCR results indicated that cellulose $b \operatorname{cs} A B C$ genes were present in both rugose and smooth strains.

Fig.1 Morphology of Cronobacter colonies grown on LB agar supplemented with Congo red and Coomassie brilliant blue for $48 \mathrm{~h}$ at $28 \mathrm{C}$. The image was taken by a digital camera

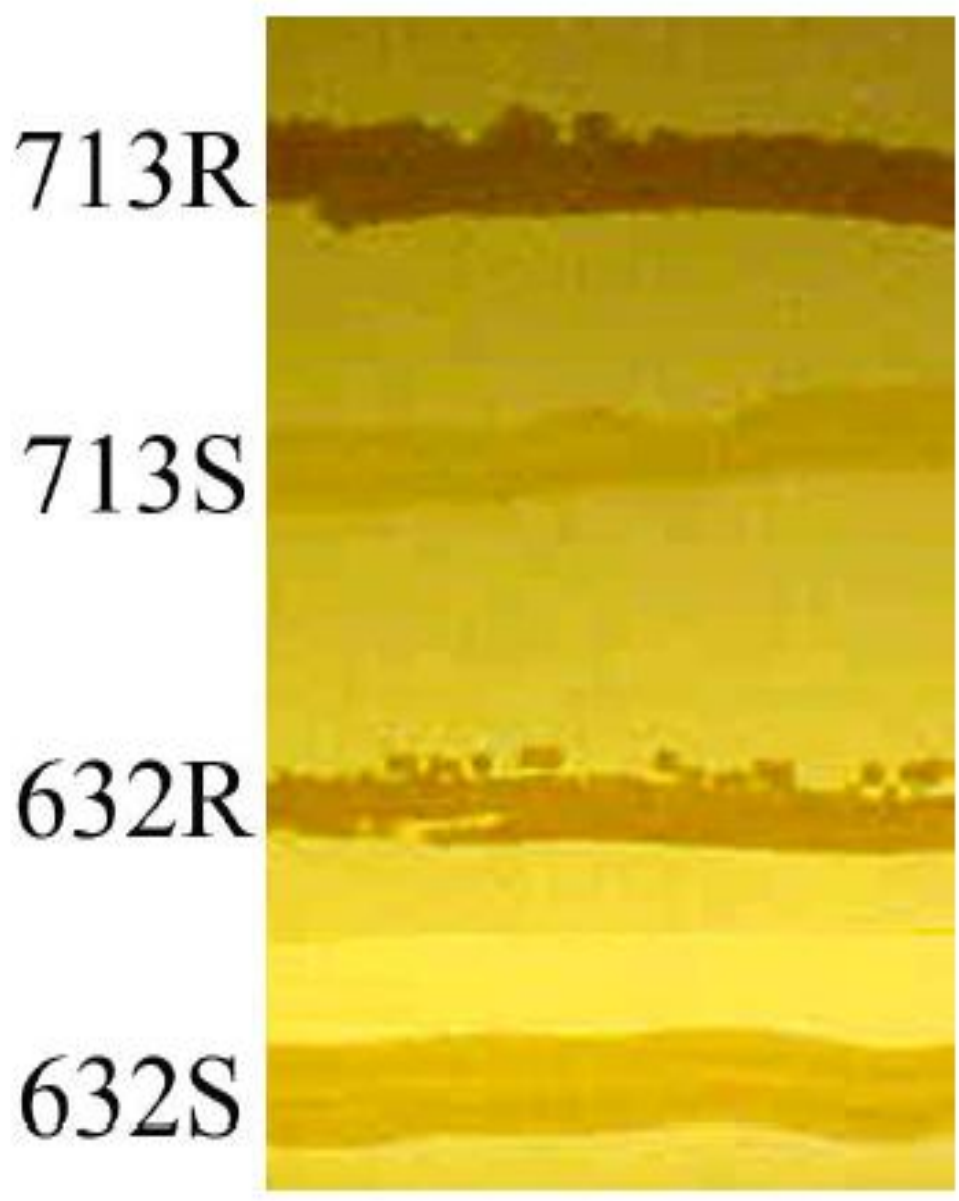


Fig.2 Measuring the biofilm formation of Cronobacter strain 713 and 632. Bacteria were cultured in LBNS broth with shaking at $37 \mathrm{C}$ (A) or $28 \mathrm{C} \mathrm{(B)} \mathrm{for} 48 \mathrm{~h}$. The biofilm formation was quantified by crystal violet staining as described in Methods. The values are the means of three independent experiments \pm SD
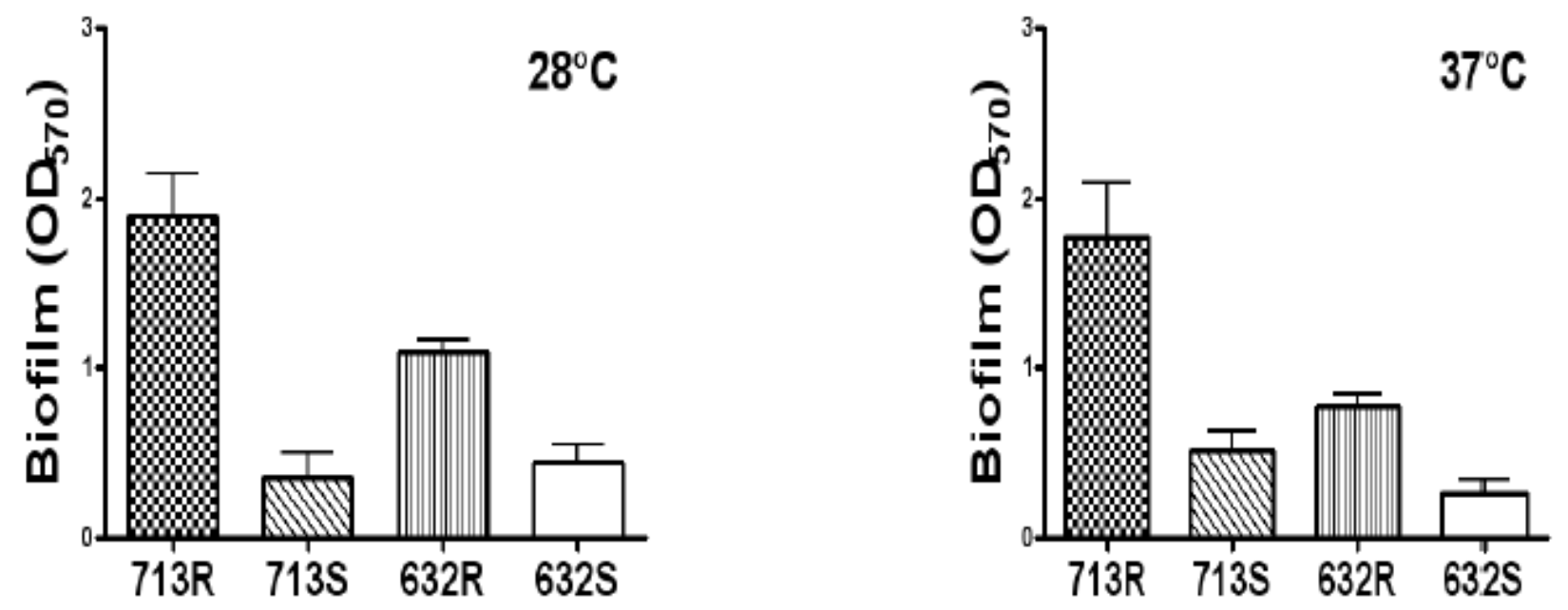

Fig.3 Molecular typing of C. sakazakii strains by PFGE. The strain 713 and 632 were digested by Xbal restriction enzyme and separated by a $1.5 \%$ agarose gel

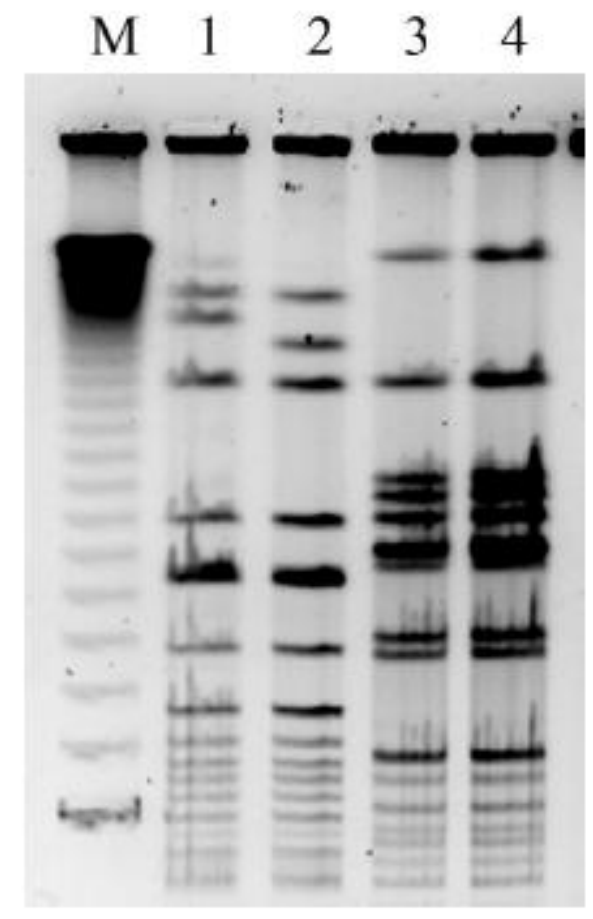

(i) 713R, (ii) 713S, (iii) 632R, (iv) 632S 
Fig.4 Images of the motility assay and EM. All strains grown overnight were inoculated into TSA motility test tubes or TSA plates, and incubated at $37 \mathrm{C}$ for $24 \mathrm{~h}$. (I) The imagines of motility of $C$. sakazakii 713R, 713R, 632R, and 632S; (II) EM observation of negative-stained $C$. sakazakii strains: A. 713R, B. 713S, C. 632R, D. 632S. All bars are 1.0 um

I

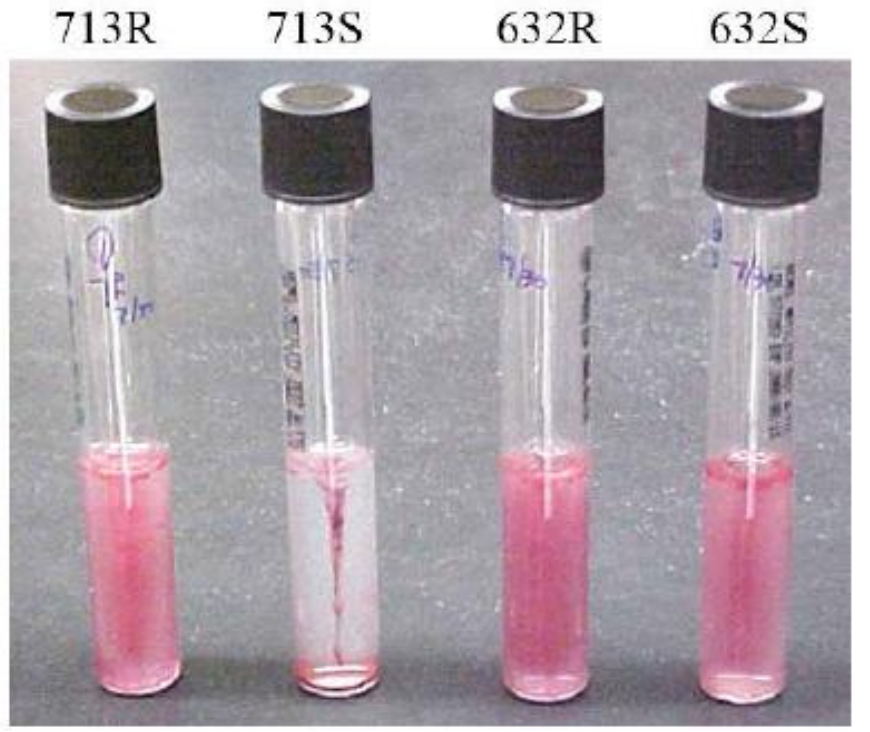

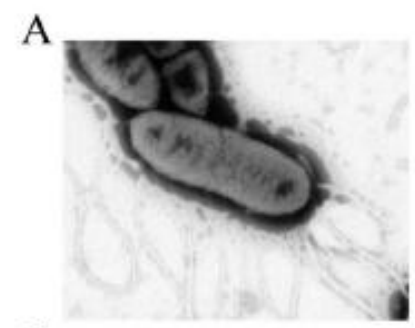

$\mathrm{C}$

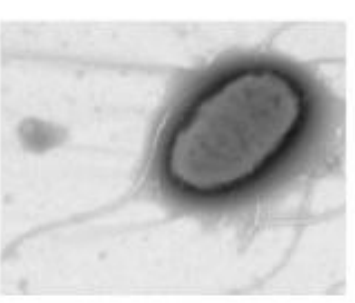

B

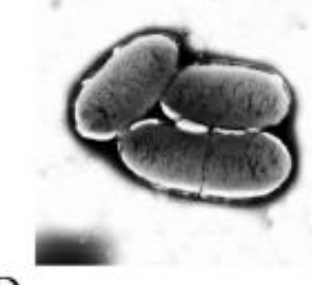

D

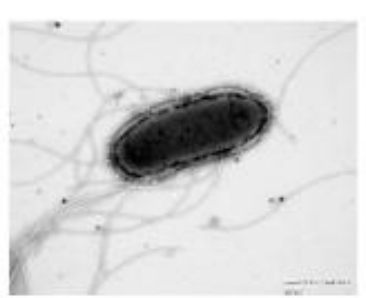

Fig.5 Morphology of Cronobacter colonies grown on LB agar supplemented with Calcofluor for $48 \mathrm{~h}$ at $28 \mathrm{C}$. The picture was taken by a digital camera.

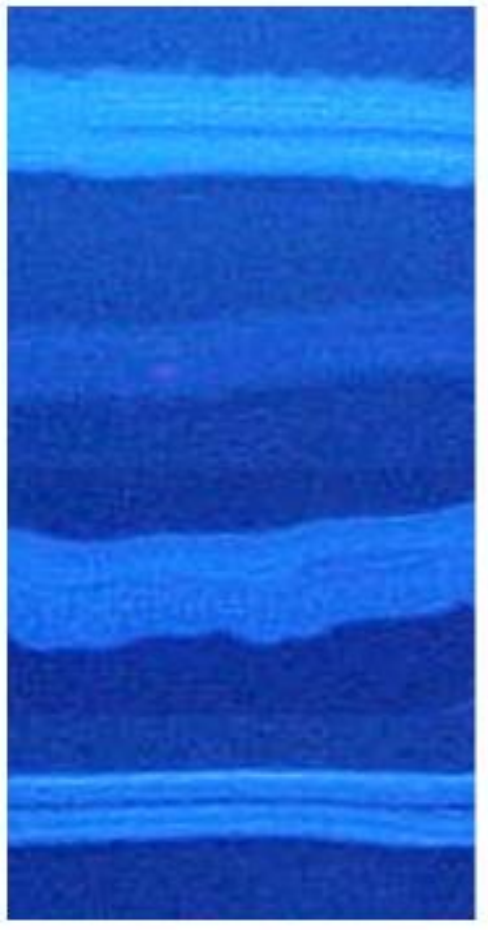

$713 \mathrm{R}$

$713 \mathrm{~S}$

$632 \mathrm{R}$

$632 \mathrm{~S}$ 
Table.1 PCR primers used in this study

\begin{tabular}{|c|c|c|c|c|}
\hline \multicolumn{2}{|c|}{ Targeted gene Primer } & Primer sequence & Amplicon size (bp) & Source \\
\hline$b c s A$ & $\begin{array}{l}b c s A-12 \mathrm{sF} \\
b c s A-12 \mathrm{sR}\end{array}$ & $\begin{array}{l}\text { gatggtaacgacatgtgggatg } \\
\text { gataaacgacactatccaggaaacc }\end{array}$ & 1296 & This study \\
\hline$b c s B$ & $\begin{array}{l}b c s B-2 \mathrm{sF} \\
b c s B-2 \mathrm{sR}\end{array}$ & $\begin{array}{l}\text { gtgaaactgctggtgattgaag } \\
\text { gaataatcgagaccgagccata }\end{array}$ & 1195 & This study \\
\hline$b c s C$ & $\begin{array}{l}b c s C-2 \mathrm{sF} \\
b c s C-2 \mathrm{sR}\end{array}$ & $\begin{array}{l}\text { ctggtatcagcagattcagggtat } \\
\text { gattagccgtctccatcagttc }\end{array}$ & 1085 & This study \\
\hline fliC & $\begin{array}{l}f l i C-1 \mathrm{sF} \\
f l i C-1 \mathrm{sR}\end{array}$ & $\begin{array}{l}\text { atgacctctcaggttaaaggtatgac } \\
\text { agacagtacagaagtaccagcctgt }\end{array}$ & 636 & This study \\
\hline$f l g E$ & $\begin{array}{l}\text { flgE-1sR } \\
\text { flgE-1sF }\end{array}$ & $\begin{array}{l}\text { atgttgaccagttctttaatcaggtc } \\
\text { acctgaagctgtactacgtgaaaac }\end{array}$ & 559 & This study \\
\hline$f \lg K$ & $\begin{array}{l}\text { flg }-1 \mathrm{sF} \\
\text { flgK }-1 \mathrm{sR}\end{array}$ & $\begin{array}{l}\text { atgtagtactgctgatagcgttgc } \\
\text { gtaaggcttcttaagctcggttct }\end{array}$ & 662 & This study \\
\hline
\end{tabular}

Table.2 Comparison of cell aggregation properties in C. sakazakii rugose and smooth pairs

\begin{tabular}{|c|c|c|}
\hline Strain & & Cell aggregation \\
\hline & $37 \mathrm{C}$ & $28 \mathrm{C}$ \\
\hline 713R & +++ & +++ \\
\hline $713 S$ & + & - \\
\hline $632 \mathrm{R}$ & ++ & ++ \\
\hline $632 S$ & + & + \\
\hline
\end{tabular}

Note: "+" and "-" represent: undetectable (-), weak (+), strong reaction (++), Stronger reaction (+++) in the assay.

Table.3 Long-term survival of C. sakazakii in biofilms on the surface of glasses

\begin{tabular}{|c|c|c|}
\hline \multirow[t]{2}{*}{ Strain } & \multicolumn{2}{|c|}{ Bacteria survival for 5 smooth on glass } \\
\hline & $37 \mathrm{C}^{*}$ & $28 \mathrm{C}^{*}$ \\
\hline $713 R$ & $2.00 \times 10^{7} \pm 5.17 \times 10^{6}$ & $8.1 \times 10^{6} \pm 1.16 \times 10^{6}$ \\
\hline $713 S$ & $5.50 \mathrm{x} \quad 10^{2} \pm 2.06 \times 10^{2}$ & $3.25 \pm 5.63$ \\
\hline $632 \mathrm{R}$ & $3.88 \times 10^{5} \pm 1.10 \times 10^{5}$ & $1.58 \times 10^{6} \pm 1.19 \times 10^{5}$ \\
\hline $632 \mathrm{~S}$ & $2.00 \times \quad 10 \pm 2.89 \times 10$ & $6.57 \times 10 \pm 4.39 \times 10$ \\
\hline
\end{tabular}

*Bacteria were cultured at $37 \mathrm{C}$ or $28 \mathrm{C}$ for 2 days. 
Table.4 PCR analysis with primers targeting $b c s A B C$ genes

\begin{tabular}{|c|c|c|c|c|c|c|}
\hline strain & $b c s A$ & $b c s B$ & $b c s C$ & fliC & $f l g E$ & $f \lg K$ \\
\hline 713R & + & + & + & + & + & + \\
\hline $713 \mathrm{~S}$ & + & + & + & - & + & + \\
\hline $632 \mathrm{R}$ & + & + & + & + & + & + \\
\hline $632 \mathrm{~S}$ & + & + & + & + & + & + \\
\hline
\end{tabular}

Expression of cellulose in the strains was tested by Calcofluor binding assay. The bacteria were inoculated in LBNS agar supplemented with Calcofluor, and cultivated at $28 \mathrm{C}$ for $48 \mathrm{~h}$. The colonies of strain $713 \mathrm{R}$, 632R, and 632S emitted strong fluorescence, however, 713S showed no fluorescence under a 366 nm UV light (Fig. 5). Because of the PCR results, the deficient expression of cellulose in strain $713 \mathrm{~S}$ was clearly not caused by lacking $b c s A B C$ genes.

\section{Detection of flagella genes in the rugose and smooth pairs}

Bacterial motility is mostly driven by flagella (Ridgway et al., 1977). A set of primers were designed to check flagella genes in the two pairs (Table 1). fliC encodes flagellin (FliC), which is a flagellin monomer while $f l g E$ encodes a flagellar hook protein and $f l g K$ encodes a hook-associated protein. The PCR results are shown in Table 4. flgE and $f l g K$ were positive in all of the tested strains. fliC presented in all of the strains except strain 713S. The negative PCR result of flagellin gene $f l i C$ in $713 \mathrm{~S}$ may be the reason why motility or flagella were absent in $713 \mathrm{~S}$ in the motility test or the EM analysis.

Once excreted from the host, enteric pathogens face to harsh environments characterized by limited nutrients, high or low temperatures, acid, osmotic stress, and dryness (Winfield and Froisman, 2003). The rugose morphology is considered to help Vibrio and Salmonella survival in the stressful environments (White and Surette, 2006). In this study, we identified and defined rugose and smooth phenotypes in $C$. sakazakii. Based on these results, we showed the advantages of rugose phenotype in survival and persistence of $C$. sakazakii. Rugose variants produced more biofilms and cell aggregation than their smooth phase variant counterparts. The capacity of Cronobacter to switch between smooth to rugose phase phenotypes increase bacterial resistances to temperature and desiccative stresses; thus contributes to their survival in harsh environments. In contrast with Vibrio, the rugose morphology of Salmonella and other bacteria do not produce Vps. The rugosity of Salmonella species and pathogenic E. coli are reported to related to the expression of cellulose, curli, lipopolysaccharide (LPS), capsules or other polysaccharides (Kim and Wei, 2009). We try to find if the rugosity of Cronobacter related to curli and cellulose.

C. sakazakii do not possess curli $\operatorname{csg} B A C$ and csgDEFG genes (Hu, unpublished data). Both rugose and smooth pairs tested here possessed cellulose $b c s A B C$ genes using the PCR assay (Table 4). Furthermore, the rugose variants could form biofilms as much at $37 \mathrm{C}$ as at 28 $\mathrm{C}$, and the biofilms could form when the bacteria were cultured in rich culture media 
with $1 \%$ sodium chloride. In contrast to that, the biofilms formation associated with curli and cellulose usually occurred at lower temperature and low osmotic media (no salt or low salt); however, the biofilm formation and cell aggregation of the rugose strains could occur at $37 \mathrm{C}$ and high osmotic condition. Thus, the difference between the rugose and smooth pairs in biofilm formation, cell aggregation, and long-term survival indicated that some unknown factors might mediate the smooth to rugose phase change except curli and cellulose (Hu et al., 2015; $\mathrm{Hu}$, unpublished data).

To understand what differences exist between rugose and smooth strains, a molecular typing (PFGE) and a colorimetric typing (VITEK) were used to detect potential differences. After genomic DNA of the organisms was separated by PFGE, no remarkable differences between the rugose and smooth pairs were found in PFGE typing except for two different bands between 713R and 713S. Furthermore, no differences in VITEK typing were shown between the rugose and smooth pairs. These results suggest that no obvious genomic and biochemical differences are found between the rugose and smooth variants using the assays.

Cronobacter could form biofilm, however, the quantity of biofilm formation varied among strains. Rugose variant $713 \mathrm{R}$ produced more biofilms and auto aggregation than rugose variant $632 \mathrm{R}$. It was not clear why some rugose variant produced more biofilms than the others. The VITEK typing showed three biochemical reactions differed between strain 713 and 632. Whether the different reactions affect the quantity of biofilm formation still needs further investigation. A bacterial flagellum is comprised of a basal body, a hook and a filament (Apel and Surette, 2008). PCR primers targeted flagella hook and filament structure genes showed only filament gene $f l i C$ was absent in strain
713S. The failed expression of flagella in $713 \mathrm{~S}$ may be due to the absent of fliC gene. It is still unknown if the failed expression of the filament or other factors in $713 \mathrm{~S}$ caused no significant fluorescence in strain $713 \mathrm{~S}$ in Calcofluor binding assay. However, it is clear that the absent of $f l i C$ in strain $713 \mathrm{~S}$ did not relate to the rugose and smooth phase changes. From our results, the rugosity of $C$. sakazakii strain 713R and 632R were not involved in curli or cellulose. Other possible contributing factors may be LPS, extracellular polysaccharides, and capsules, or regulatory factors (Anriany et al., 2001; de Rezende et al., 2005).

Taking together, our data revealed that the rugose phenotype of Cronobacter formed more biofilms and cell autoaggregation, and enhanced the resistance to desiccated stress. The rugose variants of Cronobacter could survive longer than their smooth counterparts in the desiccated environment. Furthermore, Cronobacter rugosity did not associate with expression of curli and cellulose. PFGE and VITEK typing analyses of the pairs showed no significant differences between the rugose and smooth pairs in the assays. These results suggest that the smooth to rugose phenotype change may play an important role in Cronobacter survival and persistence in environments.

\section{Acknowledgements}

The authors thank Dr. Ben D. Tall for his guidance and critical review of the manuscript, and thank Dr. Junia J. GillesBeauburn, Dr. Mahendra H. Kothary, and Dr. Barbara A. McCardell for their technical assistances and valuable comments.

\section{References}

Anriany, Y.A., Weiner, R.M., Johnson, J.A., De Rezende, C.E., Joseph, S.W. 2001. Salmonella enterica serovar 
Typhimurium DT104 displays a rugose phenotype. Appl. Environ. Microbiol. 67: 4048-56.

Apel. D., Surette. M.G. 2008. Bringing order to a complex molecular machine: the assembly of the bacterial flagella. Biochim. Biophys. Acta. 1778: 1851-8.

Beuchat, L.R., Kim, H., Gurtler, J.B., Lin, L.C., Ryu, J.H., Richards, G.M. 2009. Cronobacter sakazakii in foods and factors affecting its survival, growth, and inactivation. Int. J. Food. Microbiol. 136: 204-13.

Beyhan, S., Bilecen, K., Salama, S.R., Casper-Lindley, C., Yildiz, F.H. 2007. Regulation of rugosity and biofilm formation in Vibrio cholerae: comparison of VpsT and VpsR regulons and epistasis analysis of vpsT, vpsR, and hapR. J. Bacteriol. 189: 388-402.

Breeuwer, P., Lardeau, A., Peterz, M., Joosten, H.M. 2003. Desiccation and heat tolerance of Enterobacter sakazakii. J. Appl. Microbiol. 95: 96773.

Carter, L., Lindsey, L.A., Grim, C.J., Sathyamoorthy, V., Jarvis, K.G., Gopinath, G., Lee, C., Sadowski, J.A., Trach, L., Pava-Ripoll, M., McCardell, B.A., Tall, B.D., Hu, L. 2013. Multiplex PCR assay targeting a diguanylate cyclase-encoding gene, $\operatorname{cgcA}$, to differentiate species within the genus Cronobacter. Appl. Environ. Microbiol. 79: 734-7.

Chapman, M.R., Robinson, L.S., Pinkner, J.S., Roth, R., Heuser, J., Hammar, M., Normark, S., Hultgren, S.J. 2002. Role of Escherichia coli curli operons in directing amyloid fiber formation. Science. 295: 851-5.

De Rezende, C.E., Anriany, Y., Carr, L.E., Joseph, S.W., Weiner, R.M. 2005. Capsular polysaccharide surrounds smooth and rugose types of Salmonella enterica serovar Typhimurium DT104.
Appl. Environ. Microbiol. 71: 7345-51.

Farmer, J.J., Asbury, M.A., Hickman, F.W. Brenner D.J. and The Enterobacteriaceae Study Group. 1980. Enterobacter sakazakii: A new species of "Enterobacteriaceae" isolated from clinical specimens. Int. J. Syst. Bacteriol. 30: 569-84.

Grau, B.L., Henk, M.C., Pettis, G.S. 2005. High-frequency phase variation of Vibrio vulnificus 1003: isolation and characterization of a rugose phenotypic variant. J. Bacteriol. 187: 2519-25.

Gualdi, L., Tagliabue, L., Bertagnoli, S., Ieranò, T., De Castro, C., Landini, P. 2008. Cellulose modulates biofilm formation by counteracting curlimediated colonization of solid surfaces in Escherichia coli. Microbiology. 154: 2017-24.

Gurtler, J.B., Beuchat, L.R. 2007. Survival of Enterobacter sakazakii in powdered infant formula as affected by composition, water activity, and temperature. J. Food Prot. 70: 1579-8.

Herschleb, J., Ananiev, G., Schwartz, D.C. 2007. Pulsed-field gel electrophoresis. Nat. Protoc. 2: 677-84.

Himelright, I., Harris, E., Lorch, V., Anderson, M., Jones, T., Craig, A., et al., 2002. Enterobacter sakazakii infections associated with the use of powdered infant formula-Tennessee, 2001. JAMA. 287: 2204-5.

Hollenbeck, E.C., Fong, J.C., Lim, J.Y., Yildiz, F.H., Fuller, G.G., Cegelski, L. 2014. Molecular determinants of mechanical properties of $V$. cholerae biofilms at the air-liquid interface. Biophys. J. 107: 2245-52.

Hu, L., Grim, C.J., Franco, A.A., Jarvis, K.G., Sathyamoorthy, V., Kothary, M.H., McCardell, B.A., Tall, B.D., 2015. Analysis of the cellulose synthase operon genes, $b c s A, b c s B$, and $b c s C$ in Cronobacter species: Prevalence among 
species and their roles in biofilm formation and cell-cell aggregation. Food Microbiol. 52: 97-105.

Hunter, C.J., Bean, J.F. 2013. Cronobacter: an emerging opportunistic pathogen associated with neonatal meningitis, sepsis and necrotizing enterocolitis. $J$. Perinatol. 33: 581-585.

Iversen, C., Mullane, N., McCardell, B., Tall, B.D., Lehner, A., Fanning, S., Stephan, R., Joosten, H. 2008. Cronobacter gen. nov., a new genus to accommodate the biogroups of Enterobacter sakazakii, and proposal of Cronobacter sakazakii gen. nov., comb. nov., Cronobacter malonaticus sp. nov., Cronobacter turicensis sp. nov., Cronobacter muytjensii sp. nov., Cronobacter dublinensis sp. nov., Cronobacter genomospecies 1, and of three subspecies, Cronobacter dublinensis subsp. dublinensis subsp. nov., Cronobacter dublinensis subsp. lausannensis subsp. nov. and Cronobacter dublinensis subsp. lactaridi subsp. Nov. Int. J. Syst. Evol. Microbiol. 58: 1442-7.

Jaradat, Z.W., Al Mousa, W., Elbetieha, A., Al Nabulsi, A., Tall, B.D. 2014. Cronobacter spp. - opportunistic foodborne pathogens. A review of their virulence and environmental-adaptive traits. J. Med. Microbiol. 63: 1023-37.

Joseph, S., Cetinkaya, E., Drahovska, H., Levican, A., Figueras, M.J., Forsythe, S.J., 2012. Cronobacter condimenti sp. nov., isolated from spiced meat, and Cronobacter unversalis sp. nov., a species designation for Cronobacter sp. genomospecies 1, recovered from a leg infection, water and food ingredients. Int. J. Syst. Evol. Microbiol. 62: 127783.

Kim, S.H., Wei, C.I. 2009. Molecular characterization of biofilm formation and attachment of Salmonella enterica serovar typhimurium DT104 on food contact surfaces. J. Food Prot. 72: 1841-7.

Lin, L.C., Beuchat, L.R. 2007. Survival of Enterobacter sakazakii in infant cereal as affected by composition, water activity, and temperature. Food Microbiol. 24: 767-77.

Morris, J.G. Jr., Sztein, M.B., Rice, E.W., Nataro, J.P., Losonsky, G.A., Panigrahi, P., Tacket, C.O., Johnson, J.A. 1996. Vibrio cholerae $\mathrm{O} 1$ can assume a chlorine-resistant rugose survival form that is virulent for humans. J. Infect. Dis. 174: 1364-8.

Rice E.W., Johnson C.J., Clark R.M., Fox K.R., Reasoner D.J., Dunnigan M.E., Panigrahi P, Johnson J.A., Morris J.G. Jr. 1992. Chlorine and survival of "rugose" Vibrio cholerae. Lancet. 340: 7403.

Ridgway, H.G, Silverman, M., Simon, M.I. 1977. Localization of proteins controlling motility and chemotaxis in Escherichia coli. J. Bacteriol. 132: 65765.

Stoop, B., Lehner, A., Iversen, C., Fanning, S., Stephan, R. 2009. Development and evaluation of rpoB based PCR systems to differentiate the six proposed species within the genus Cronobacter. Int. J. Food Microbiol. 136: 165-8.

Tall, B.D., Franco, A.A., Jarvis, K.G., Grim, C.J., Kopecko, D.J., Hu, L., Kothary, M.H., Gopinath, G., Sathyamoorthy, V., Carter, L., Curtis, S.K., Restaino, L., 2015. Chapter 38: Cronobacter species (Formerly Enterobacter sakazakii). In: Tortorello M.L. (Ed.), Compendium of Methods for the Microbiological Examination of Foods. American. Public. Health Association, Washington, DC.

Vestby, L.K., Møretrø, T., Balance, S., Langsrud, S., Nesse, L.L. 2009. Survival potential of wild type cellulose 
deficient Salmonella from the feed industry. BMC Vet. Res. 5: 43.

Wai, S.N., Mizunoe, Y., Takade, A., Kawabata, S.I., Yoshida, S.I. 1998. Vibrio cholerae O1 strain TSI-4 produces the exopolysaccharide materials that determine colony morphology, stress resistance, and biofilm formation. Appl. Environ. Microbiol. 64: 3648-55.

White, A.P., Surette, M.G. 2006. Comparative genetics of the rdar morphotype in Salmonella. J. Bacteriol. 188: 8395406.

Winfield, M.D., Groisman, E.A. 2003. Role of nonhost environments in the lifestyles of Salmonella and Escherichia coli. Appl. Environ. Microbiol. 69: 3687-94. Review.

Yildiz, F.H., Liu, X.S., Heydorn, A., Schoolnik, G.K. 2004. Molecular analysis of rugosity in a Vibrio cholerae O1 El Tor phase variant. Mol. Microbiol. 53: 497-515.

Yildiz, F.H., Schoolnik, G.K. 1999. Vibrio cholerae $\mathrm{O} 1 \mathrm{El}$ Tor: of a gene cluster required for the rugose colony type, exopolysaccharide production, chlorine resistance, and biofilm formation. Proc. Natl. Acad. Sci. U.S.A. 96: 4028-33.

\section{How to cite this article:}

Lan Hu and Sherile K. Curtis. 2017. Characterizing the Rogues and Smooth Pairs of Cronobacter sakazakii Involved in Biofilm Formation and Long-Term Survival. Int.J.Curr.Microbiol.App.Sci. 6(10): 4720-4733. doi: https://doi.org/10.20546/ijcmas.2017.610.438 